\title{
MILITARY AND POLITICAL ASPECTS OF ONE OF THE PROBLEMS OF THE MODERN POWER INDUSTRY
}

\begin{abstract}
The problem of Intentional Destructive Electromagnetic Impacts (IDEI) on power systems has become recently more and more actual in connection with two modern trends: the extension of using microelectronics and microprocessor-based devices and systems in electric power industry - on the one hand, and the intensive design of special equipment for distance destruction of electronic devices and systems - with another. The most powerful method for such destruction is the High-altitude Electromagnetic Pulse (HEMP) as a result of a high-altitude nuclear explosion. The history of experimental high-altitude nuclear explosions has been known now for over half a century. During this time quite a few scientific articles and books presenting details of this phenomenon and measures of protection from it have been published. In view of this fact, it would be possible to assume that the problem of protection against HEMP has been solved for a long time and modern power systems are well protected from this phenomenon. However the research performed by the author displays that actually it has not and for the past decades in one country of the world, at least, no practical measures have been taken for the protection of the national infrastructures against HEMP and all action has been restricted only to writing reports, recommendations and guidelines. In the paper the reasons for such situation (in particular, political and military aspects of the problem) are analyzed. References 50, figures 5.

Key words: High-altitude Electromagnetic Pulse, Intentional Destructive Electromagnetic Impacts, power system, national infrastructure.
\end{abstract}

Проблема преднамеренных дистанционных деструктивных воздействий (ПДДВ) на энергетические системы становится в последнее время все более и более актуальной в связи с двумя современными тенденциями: расиирением использования микроэлектроники и устройств на основе микропроцессоров в электроэнергетике - с одной стороны, и успехами, достигнутыми в разработке специальных видов оружся, предназначенных для дистанционного поражения электронных устройств - с другой. Самый мощный метод дистанционного поражения электроники - электромагнитный импульс высотного ядерного взрыва (ЭМИ ЯВ). История экспериментальных высотных ядерных взрывов насчитывает половину столетия. За это время было опубликовано множество научных статей, книг, отчетов, подробно описывающих все детали этого процесса и меры защиты от него. В связи с этим, можно было бы предположсить, что проблема защиты от ЭМИ ЯВ была за эти десятилетия успешно решена и современные электроэнергетические системы хорошо защищены от этого явления. Однако, исследование, выполненное автором, показывает, что ни в одной стране мира до сих пор не были предприняты никакие практические меры зациты национальных инфраструктур от ЭМИ ЯВ и все действия были ограничены только докладами, отчетами, рекомендациями. В данной статье проанализированы причины такой ситуации (в частности, политические и военные аспекты проблемы). Библ. 50 , рис. 5.

Ключевые слова: электромагнитный импульс высотного ядерного взрыва, преднамеренные деструктивные электромагнитные воздействия, энергосистема, национальная инфраструктура.

\section{«...our vulnerability is increasing daily as our use of and dependence on electronics continues to grow in both our civil and military sectors» Dr. William R. Graham, EMP Commission's Chairman}

Introduction. The possibility using special weapons that can destroy an electric power system and other important elements of national infrastructure without a direct impact on a person is very alluring as it can result in a collapse of the whole country. Moreover, people responsible for decision-making about weapon employment cannot be charged for the indiscriminate killing of civilians, since this type of weapon does not impact on people directly. This type of weapon is represented by systems, which generate extra-powerful electromagnetic fields knocking electronic and electrically powered equipment out of service.

The problem of Intentional Destructive Electromagnetic Impacts (IDEI) impact on electric power systems has only recently become extremely relevant due to two modern trends: expanded use of micro-electronics and micro-processor equipment in the electric power industry on the one hand, and the intensive development of means for remote destruction of electronic instruments on the other hand [1]. Furthermore, the problem is relevant not only to such solely civilian fields as the electric power industry, but also to military personnel as military facilities and ranges receive electric energy and water from the civilian systems, serious malfunctioning of which would inevitably affect the defense condition of an army with all its armament systems protected from IDEI.

Brief Historical Background. The devastating impact of a remote nuclear explosion on electronic equipment was discovered during the initial trials of this new (for that time) type of weapon. Later on, theoretic substantiation of a High Altitude Electromagnetic Pulse (HEMP) of a nuclear explosion was found in the academic works of Nobel Prizewinner for physics Arthur Compton, dating back to 1922 . Military men have quickly appreciated the advantage of using this phenomenon as a weapon that can destroy the infrastructure and electric power systems of a rival at one go. The first attempts to study HEPM were conducted by the Atomic Energy Commission and the Nuclear Safety Agency of the US Department of Defense on July 9, 1962 (the project encoded «Starfish Prime»). A thermo-nuclear warhead missile with a capacity of 1.44 Mega-tons was launched from a US military range located on Johnston Attol between Marshall and Hawaii Islands in Pacific Ocean. It reached

(C) V. Gurevich 
the height of $450 \mathrm{~km}$ and was deliberately exploded. This trial was one out of five high altitude nuclear explosions aimed at studying HEMP in the USA in 1962 within the framework of a more extensive project encoded «Operation Fishbowl». During these trials powerful electro-magnetic pulses were registered, which could vastly affect electronic equipment, communication and overhead transmission lines, radio transmission station and radars. They even knocked out street lighting in Hawaii, which is located about $1,500 \mathrm{~km}$ from the center of explosion [2].

In 1962 (on October 22, October 28 and November 1) the Soviet Union also conducted a series of high altitude nuclear explosions (each with a capacity of $300 \mathrm{kt}$ ) under the project called «Project-K» - K3-184; K4-187 and K5195 - the aim of which was to study the HEMP phenomenon. The warhead missiles were launched from the Kapustin Yar missile launchpad in the Astrakhan region and were deliberately exploded at the heights of $60-290$ $\mathrm{km}$ above the territory of the military range in the SaryShagan, Karaganda region, Kazakhstan (a restricted access territorial subdivision Priozyorsk). In the USSR, the research of HEMP and preparation of those nuclear test explosions were conducted by Central Institute of Physics and Technology of Federal Ministry of Defense - CIPT (military unit 51105 or Central R\&D Institute-12) in Sergiyev Posad, Moscow (now - Federal State Institution «12 Central R\&D Institute of MoD of Russian Federation»). During one of these trials (K3-184) impulse current of up to $3400 \mathrm{~A}$ was registered in aerial telephone line cables, which resulted in an emerging of pulse voltage with an amplitude of up to $28 \mathrm{kV}$; actuation of all the arresters installed in the equipment and blowing of all the fuses accompanied by shutdown of communication system; damage of radio communication systems located $600 \mathrm{~km}$ away from the center of explosion; outage of a radio stations located $1000 \mathrm{~km}$ away; damage of transformers and power generators at power plants; insulator punctures of overhead transmission lines (fig. 1). Serious damage of equipment was also reported at Baikonur Cosmodrome. It should be noted that this refers to equipment manufactured in 1960s, i.e., the one using electromechanical elements and vacuum tubes, which is much more resistant to IDEI than modern digital and micro-processor based equipment.

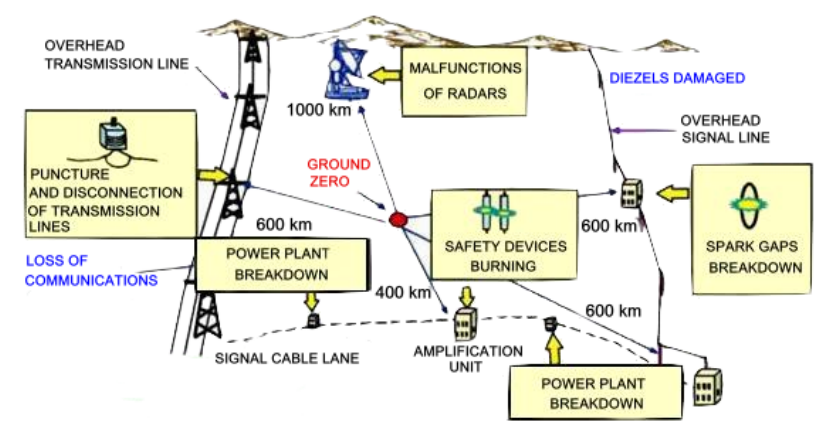

Fig. 1. Illustration of equipment damages caused by highaltitude HEMP impact above Kazakhstan in 1962. For the first time the picture was presented in English during the EUROEM conference by the Head of Central R\&D Institute-12, Major General, Prof. Dr. Mr. V.M. Loborev in France in 1994 [3]

Moreover, both American and Soviet researchers used thermo-nuclear explosives the electromagnetic pulse of which appeared to be 3-5 fold weaker than that emerg-

ing upon detonation of a ordinary nuclear explosive of the same capacity.

The first valid information about HEMP and methods of protection in electric power industry. It is obvious that due to complexity, importance and high costs of test nuclear explosions the information about them was strictly confidential, so the first users of this information were military specialists. It is speculated that the first disclosure of such information dates back to the «Perestroyka» era, when it was presented by the Head of Central Physical and Technical Institution of the Ministry of Defense Major General Mr. V.M. Loborev during his reknowned speech at the EUROEM Conference in France in 1994. However, this is not true. It appears that the first publications of detailed and authentic evidence of HEMP parameters and its impact on the country's infrastructure, in particular the power supply systems, date back to late $60 \mathrm{~s}$ - early $70 \mathrm{~s}$ of the last century. In other words this information has already been in public domain for 40-50 years [4-23]. Moreover, some of these publications, (for instance $[16,18]$ ) also contain description of protection measures against HEMP impact. The majority of these sources were published in the USA, so a conclusion can be made that the USA achieved unbeatable results in the field of protection of the most important components of their national infrastructure from HEMP over the last half of the century. Furthermore, the army should also be interested in this.

The actual state of the art in the field of protection of power systems from HEMP and other types of IDEI.

"You can fool all the people some of the time; and some of the people all the time; but you cannot fool all the people all the time». Abraham Lincoln

So, what is really happening in the USA and in the world in terms of protection of electric power industry and other extremely important systems constituting the country's infrastructure from IDEI impact? Perhaps, many things are happening based on the quantity of both governmental and private entities dealing with this problem, which are financed from the country's budget at least in the USA. Here is the list of some of them:

- Metatech Corp.;

- Department of Homeland Security (DHS);

- EMP Commission of Congress;

- North American Electric Reliability Corp. (NERC);

- Department of Energy;

- Department of Defense (DoD);

- Critical Infrastructure Partnership Advisory Council (CIPAC);

- Electric Infrastructure Security Council (EICS);

- Defense Science Board (DSB);

- US Strategic Command (USSTRATCOM);

- Defense Threat Reduction Agency (DTRA);

- Defense Logistics Agency (DLA);

- Air Force Weapons Laboratory;

- FBI;

- Sandia National Laboratories;

- Lawrence Livermore National Laboratory (LINL); 
- Oak Ridge National Laboratory;

- Idaho National Laboratories;

- Los Alamos National Laboratories;

- Martin Marietta Energy Systems, Inc.;

- National Security Telecommunications Advisory Committee;

- Federal Emergency Management Agency (FEMA);

- National Academy of Science;

- Task Force on National and Homeland Security;

- EMPrimus;

- Neighborhood of Alternative Homes (NOAH);

- EMPact America;

- Federal Energy Regulatory Commission (FERC);

- Electric Power Research Institute (EPRI);

- NASA;

- U.S. Northern Command (NORTHCOM);

- SHIELD Act;

- EMP Grid;

- EMP Technology Holding;

- Strategic National Risk Assessment (SNRA);

- Walpole Fire Department.

International organizations with USA participation:

- International Electrotechnical Commision (IEC), Technical Subcommittee 77C

- CIGRE, Working Group WG C4.206

Doesn't it seem suspicious that so many organizations from only one country are taking an active part in the subject supported by a huge number of published articles during the last decades and having no «white spots», which need to be further investigated? It appeared that the IDEI topic and particularly HEMP is nothing else than a wonderful «long-playing» tool of «bugging» the State budget. And it looks like nobody wants the «bugging» process to be finished by some certain actions aimed at the protection of electric power systems. To support this let me cite one of the former authorities of the US Ministry of Defense Dr. Ashton Carter: «The Army, Navy and Strategic Command continue to think about thinking about the problem». Dr. Peter Vincent Pry, director of the Task Force on National and Homeland Security said more specifically on this topic: "The problem is not the technology. We know how to protect against it. It's not the money, it doesn't cost that much. The problem is the politics. It always seems to be the politics that gets in the way«. In his book called «Apocalypse Unknown» (fig. 2), Dr. Pry complains at the fact that the situation is much better in some other countries (Israel, UK and Russia) compared to the USA, because they've already started the realization of some practical steps towards protection of electric systems.

Let us calm Dr. Pry down. He doesn't need to be worried about the lagging of the USA. In actuality the situation in this area in, say, Russia is much worse than that in the USA, since the electric engineers there either didn't hear about the problem at all, or treat it as «Gurevich's horror stories» (as the only author writing on this topic in the Russian language literature is the author of this article). The situation is not better in other countries. So, it becomes clear why nothing specific has been done anywhere in the world regarding protection of electric power industry from IDEI and why all the efforts are limited by multi-page reports about investigations, presentations, workshops, conferences and other types of pleasant leisure in a circle of colleagues. The fact is that those multiple «participants of the process» are not interested in finishing the long-term investigation process, but prefer to keep the topic «afloat» in order to receive governmental financial proceeds.
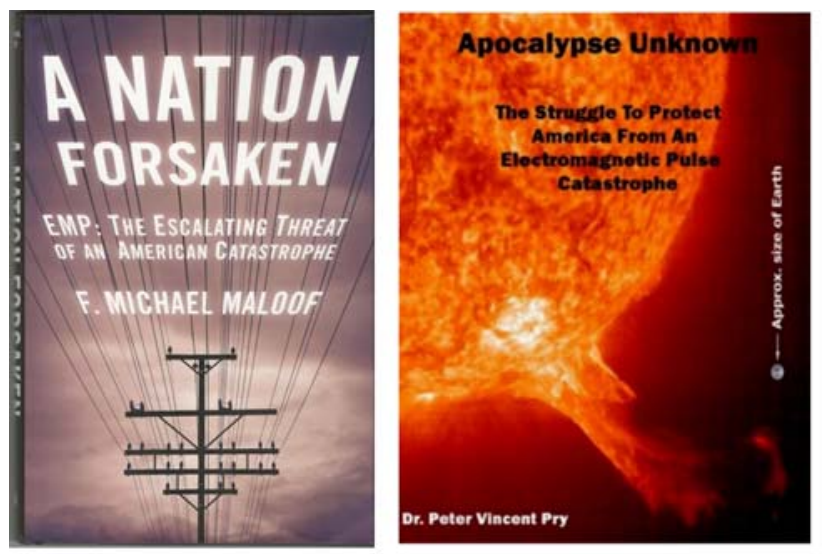

Fig. 2. The book by F. Michael Maloof «A Nation Forsaken», devoted to description of bureaucratic and political games regarding the IDEI problem in the USA (left) and the book by

Peter Vincent Pry «Apocalypse Unknown» (right)

This problem is discussed in the book of former Pentagon analyst Michael Maloof. «A Nation Forsaken» (fig. 2). The above mentioned Peter Vincent Pry also writes about serious bureaucratic hurdles related to this topic in his book called «Apocalypse Unknown».

Representatives of the powerful Military-Industrial Complex (as president Eisenhower referred to it) also contribute to delaying the realization of well-known specific measures aimed at protection of electric power systems from IDEI. They insist that the only efficient protection from electro-magnetic pulses of a nuclear explosion is represented by the national Missile Defense System (MDS) where much more budgetary funds need to be invested. This attitude of these representatives becomes clear when comparing a relatively low cost of HEMP protection means for the most important elements and systems of the national infrastructure with the costs for development and production of an efficient multi-level missile shield, which protects the whole country. As for other non-nuclear means of IDEI [1], since the MDS does not protect from them, it is easier to pretend that they do not exist and the information about them in the mass media is nothing more than a bluff aimed at scaring housewives. However, everything is not that easy. There are missile systems from which the MDS does not protect, i.e., they are not capable of protecting the national infrastructure from the impact of electro-magnetic pulses of a nuclear explosion. What kind of systems are they?

Short- and intermediate-range missiles are potential sources of HEMP, against which the MDS are back-strapped. Today the tendency is to reduce the capacity of missile nuclear warheads due to improvements of their accuracy. For example, when a relatively accurate «Scarab B» with a circular error probable (CEP) of $250 \mathrm{~m}$ was equipped with a nuclear warhead with a capacity of 
up to $200 \mathrm{kt}$ (charge type AA-92) a more accurate and new «Stone» missile (fig. 4), with a CEP of $30 \mathrm{~m}$ can be equipped with a nuclear warhead with a capacity of only $50 \mathrm{kt}$ (fig. 3). However, $50 \mathrm{kt}$ is not enough to generate powerful and efficient HEMP.

A well-publicized missile «Stone» which is claimed to be unique appears to be not that unique in reality. Israeli missiles LORA (LOng Range Attack) possess very similar tactical and technical specifications, features of trajectory and control system. Moreover, compared to «Stone» their CEP is smaller (CEP $=10 \mathrm{~m})$, the mass of their missile is two times less, their warhead mass is larger, they can carry a more powerful nuclear charge and they have a universal launching unit, which can be assembled on different vehicles, including ships. The launching unit of LORA system manufactured as a container with four missiles, which resembles the Russian containers Club-K with the same number of missiles $3 \mathrm{M}$ 14KE, X-35UE (fig. 4).
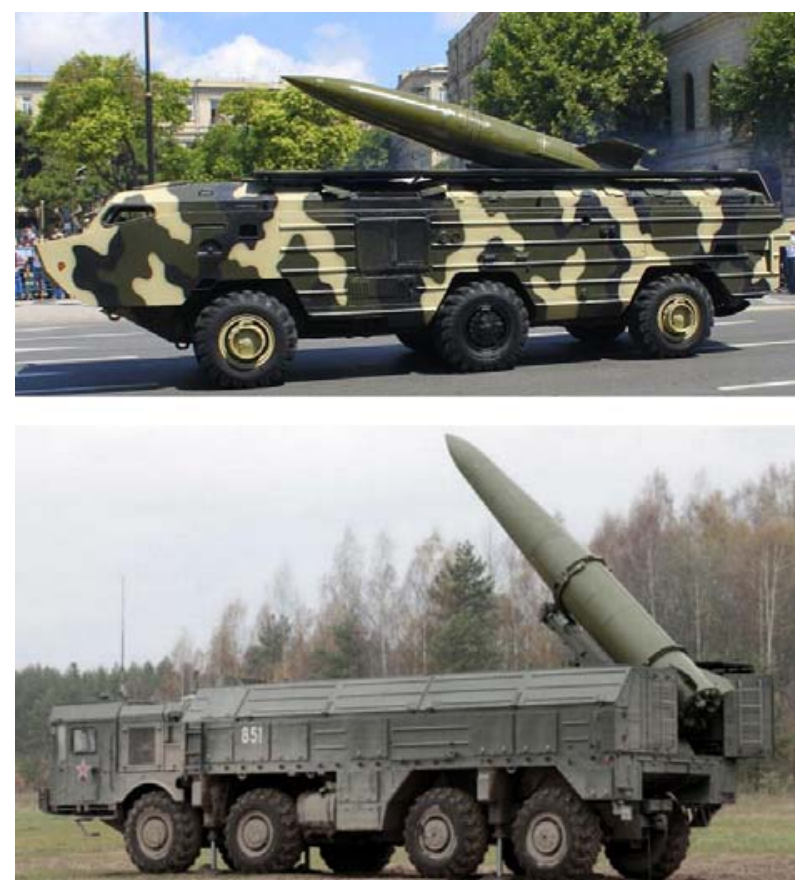

Fig. 3. Missile launchers of a battle-field support rocket SS-21 «Scarab B» (Tochka-U) - above and tactical ballistic missile system SS-26 «Stone» (Iskander-E) - below

The Club-K - Russian container-based missile unit, which can fit a standard 20- or 40-foot sea container, is intended for targeting above-water and ground targets. The unit can be installed on the coast lines, different classes of vessels, railway and truck platforms. The complex can be used with ground launching units as well as sea, railway and truck platforms. It can use the following anti-ship missiles: 3M-54KE, 3M-54KE1, X-35UE and missiles for hitting ground targets, such as $3 \mathrm{M}-14 \mathrm{KE}, \mathrm{X}-35 \mathrm{UE}$. All the missiles included in the complex are cruise missiles, flying at a relatively low altitude of $10-150 \mathrm{~m}$ and are not intended to be equipped with nuclear warheads, while LORA is equipped with tactical ballistic missile, which can fly as high as $45 \mathrm{~km}$ and can carry high capacity nuclear charges at a distance of up to $300 \mathrm{~km}$.

Why do I pay so much attention to these missile systems? Because this type of relatively small missiles fitted into standard sea containers on ships near the coast line or even in ports (fig. 5) and capable of carrying nuclear charges over hundreds of kilometers while ascending to altitudes of several tens kilometers are the sources of HEMP invulnerable to any MDS both existing and potentially developed due to their capability of concealed approach to a target, ultra-low approach time and changing trajectory during flight.

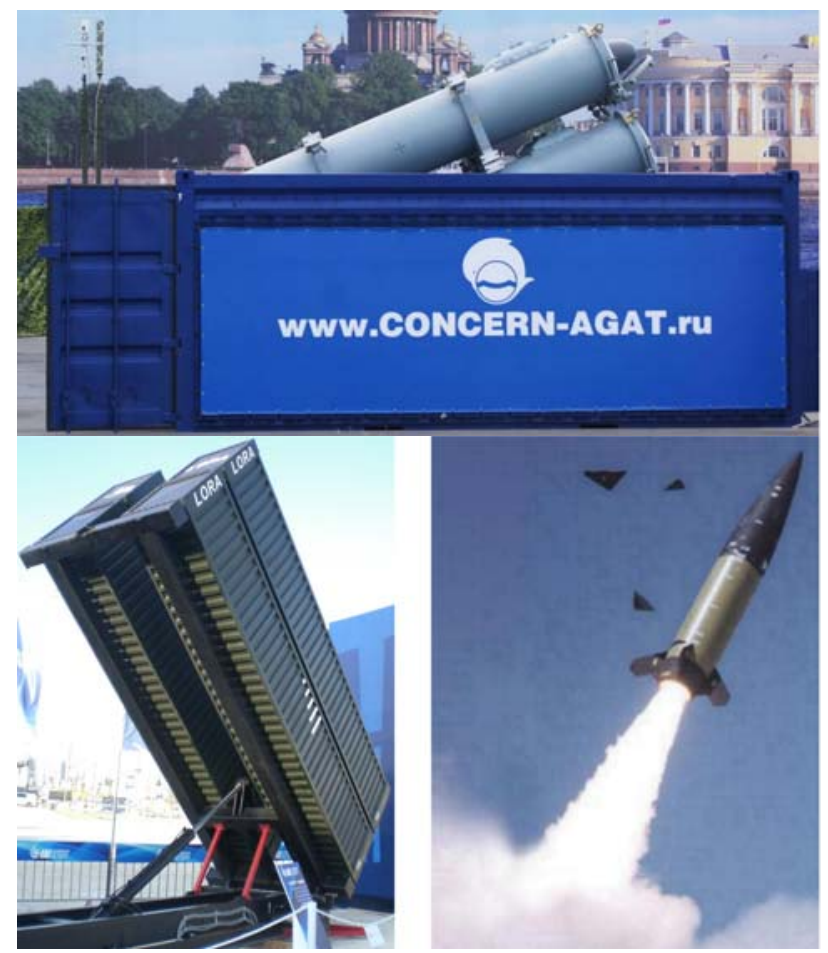

Fig. 4. Container-based launching units of missile complexes Club-K (above) and LORA (below)

The possibility of concealed approach of tactical warhead missiles of a small action radius to a target in order to avoid its interception by MDS on the one hand and to take it out of regulation of international treaties on the other hand, has long been known to specialists and the attempts to develop these systems started immediately upon creation of relatively small nuclear warhead missiles. For example, in 1961 the US airborne units received «Little John» (MGR-3) missiles, which were equipped with free-flight rockets capable of carying nuclear warheads. Light-weight launch units of this system could be delivered by $\mathrm{CH}-47$ «Chinook» helicopters both in the pit and on external lift.

The Soviet Union quickly appreciated the advantages of these systems and based on the Decree of the Council of Ministers of USSR No. 135-66 dated February 5, 1962, the development of tactical missile complex «FROG-7» (9K53) with 9M21B rockets (nuclear warhead) and 9M21B1 (thermonuclear warhead) and the launch unit 9P114 represented by a light-weight selfpropelled platform with a carburettor engine M-407 with a capacity of 45 h.p. from «Mosckvich-407» car. Later on several modifications of such systems were introduced, which allowed for transporting by MI- 6 and MI-10 cargo copters. The helicopter was expected to deliver the rocket with its launch unit behind enemy lines. The rest of the way where necessary could by covered on wheels and 
then it could suddenly strike a rocket from a position which the enemy did not consider, which translates it from a tactical complex into strategical one.
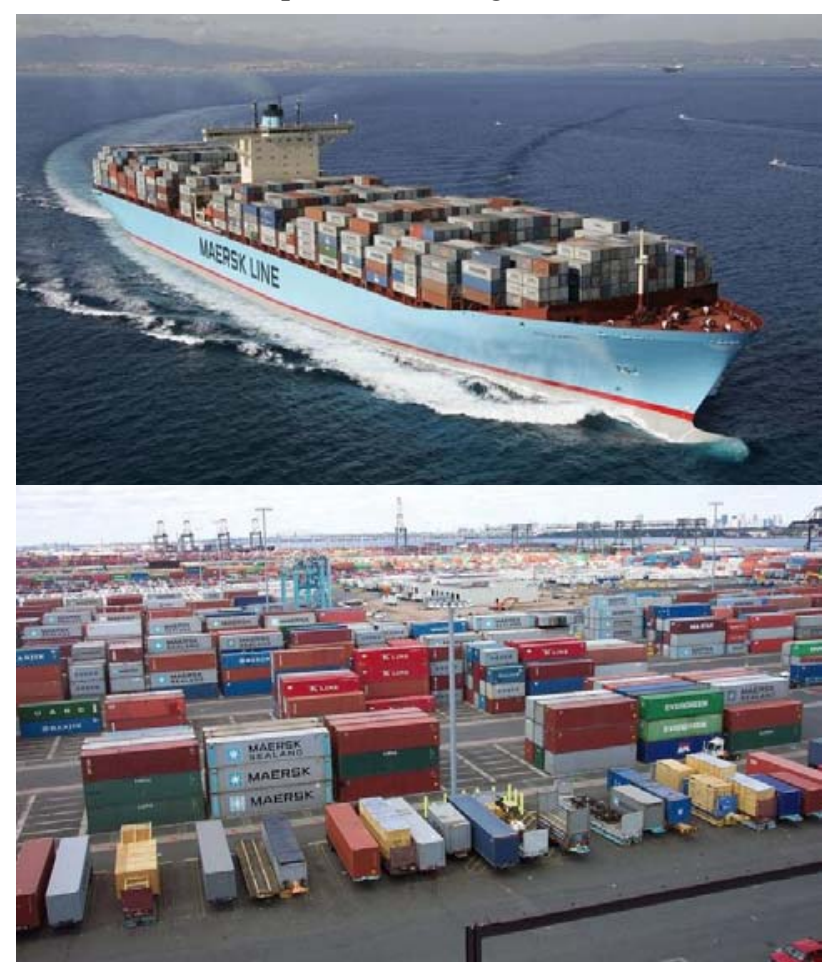

Fig. 5. Containers resting on ships and in ports where tactical ballistic nuclear warhead missiles can fit are invulnerable to MDS

The efforts of «FROG-7» development reached the stage of experimental samples testing. However, this resulted in many obstacles including high «windage» of a helicopter carrying a launch unit and consequently high drifting rate as well as inappropriate flying range of fully loaded helicopters. As a result the efforts on development of this complex were discontinued in 1965.

Modern technological level has made it possible to return to this idea and realize it successfully. Today, there are over a hundred million standard containers circulating all over the world (fig. 5). Who knows which of them are just containers and which of them carry rockets... While Israeli LORA is actually the only fully-featured container system, which can secretly approach to the coast line of a country on a container ship and hit its territory with an electro-magnetic pulse, the fact of existence of this system allows us to conclude that the statements of MIS representatives about efficient protection of advanced MDS against HEMP and that they should continue to receive additional investments are not true and in fact are a way of deceiving public opinion. In practice an army will not be able to ensure efficient protection of energy supply systems of cities and settlements from IDEI and thus, electric engineers should take the leading role and take care of such protection.

What needs to be done in order to protect a country from an «electro-magnetic Armageddon»? Since all the necessary research efforts have already been conducted and their results and practical recommendations are published in open sources [24-34] as well as covered in multiple standards of International Electrotechnical Commission (IEC) [34-41], Institute of Electrical and
Electronics Engineers (IEEE) [42], military standards of US MoD [44-49], it is necessary to stop financing a large number of organizations speculating on this problem and using it as a source of their welfare and stream the free funds into performance of certain actions aimed at protection of electric energy systems from IDEI [50]. Those countries that do not have such branched network of organizations dealing with the problem like that of the USA should not follow the USA rather they should start creating similar entities, not doing so leads to a dead-end. The only organization that must be kept to manage the process should, in my opinion, be the National Coordination Center on IDEI problem the purpose of which would be to analyze the published literature, develop a plan of certain actions within specific time frames, assign responsible people to observe performance of these time frames, issue specific technical requirements for the organizations with regard to protection of electric power supply systems from IDEI and then organize and coordinate their efforts. The results of these efforts should not be reports and conferences (which must be simply prohibited!), but real substations and power plants protected from IDEI.

\section{REFERENCES}

1. Gurevich V. Cyber and Electromagnetic Threats in Modern Relay Protection. CRC Press, Boca Raton, London, New York, 2015. $205 \mathrm{p}$

2. Operation Dominic, Fish Bowl Series, Debris Expansion Experiment. Air Force Weapons Laboratory. Project Officer's Report, Project 6.7, Report AD-A995 428, POR-2026 (WT2026), 10 December 1965.

3. Loborev V.M. Up to date state of the NEMP problems and topical research directions. Euro Electromagnetic Conf. (EUROEM), Bordeaux, France, June 1994, pp. 15-21.

4. Kompaneets A.S. Radio emission from an atomic explosion. Journal of Experimental and Theoretical Physics, 1958, vol. 35. (Rus).

5. Karzas W.J., Latter R. Electromagnetic radiation from a nuclear explosion in space. Physical Review, 1962, vol.126, no.6, pp. 1919-1926. doi: 10.1103/physrev.126.1919.

6. Karzas W.J., Latter R. EMP from high-altitude nuclear explosions. Report No. RM-4194, Rand Corporation, March 1965. 7. Karzas W.J., Latter R. Detection of electromagnetic radiation from nuclear explosions in space. Physical Review, 1965, vol.137, no.5B, pp. B1369-B1378. doi: 10.1103/physrev.137.b1369.

8. Inston H.H., Diddons R.A. Electromagnetic pulse research. ITT Research Institute Project T1029, Chicago, Illinois 60616, Final Report, September 1965.

9. DASA EMP (electronic pulse). Handbook, by United States Defense Atomic Support Agency. Information and Analysis Center, National government publication, Santa Barbara, Calif., 1968.

10. Electromagnetic Pulse Problems in Civilian Power and Communications. Summary of a seminar held at Oak Ridge National Laboratory, August 1969, sponsored by the U.S. Atomic Energy Commission and the Department of Defense, Office of Civil Defense.

11. EMP Threat and Protective Measures. Office of Civil Defense, TR-61, August 1970.

12. Parks G.S., Dayaharsh T.I., Whitson A.L. A Survey of EMP Effects During Operation Fishbowl. Defense Atomic Support Agency (DASA), Report DASA-2415, 1970.

13. Nelson D.B. A Program to Counter the Effects of Nuclear Electromagnetic Pulse in Commercial Power Systems. Oak Ridge National Laboratory, Report ORNL-TM-3552, Part 1.8, October 1972. 
14. Marable J.H., Baird J.K., Nelson D.B. Effects of Electromagnetic Pulse of a Power System. Oak Ridge National Laboratory, Report ORNL-4836, December 1972. doi: $10.2172 / 4477360$.

15. Sandia Laboratories «Electromagnetic Pulse Handbook for Missiles and Aircraft in Flight», SC-M-71 0346, AFWL TR 7368, EMP Interaction Note 1-1, September 1972.

16. Rickets L.W. Fundamentals of Nuclear Hardening of Electronic Equipment. Wiley \& Sons Inc., 1972.

17. James K. Baird, Nicholas J. Frigo. Effects of Electromagnetic Pulse (EMP) on the Supervisory Control Equipment of a Power System. Oak Ridge National Laboratory, Report ORNL4899, October 1973. doi: 10.2172/4281389.

18. Rickets L.W., Bridges J.E., Miletta J. EMP Radiation and Protective Techniques. John Willey and Sons, New York, 1976.

19. United States High-Altitude Test Experiences: A Review Emphasizing the Impact on the Environment. Report LA-6405, Los Alamos Scientific Laboratory. October, 1976.

20. Glasstone S., Dolan P.J. The Effects of Nuclear Weapons. U.S. Department of Defense, Washington, DC, 1977.

21. Longmire C.L. On the Electromagnetic Pulse Produced by Nuclear Explosions. IEEE Trans. on Electromagnetic Compatibility, February 1978, vol. EMC-20, no.1, pp. 3-13. doi: 10.1109/temc.1978.303688.

22. Sollfrey W. Analytic Theory of the Effects of Atmospheric Scattering on the Current and Ionization Produced by the Compton Electrons from High Altitude Nuclear Explosions. Rand Corp., R-1973-AF, 1977.

23. Butler C. EMP Penetration Handbook for Apertures, Cable Shields, Connectors, Skin Panels. AFWL-TR-77-149, Air Force Weapons Laboratory (The Dikewood Corporation), December, 1977.

24. HEMP Emergency Planning and Operating Procedures for Electric Power Systems. Oak Ridge National Laboratory, Report ORNL/Sub/91-SG105/1, 1991.

25. Impacts of a Nominal Nuclear Electromagnetic Pulse on Electric Power Systems. Oak Ridge National Laboratory, Report ORNL/Sub/83-43374, 1991.

26. HEMP-Induced Transients in Electric Power Substations Oak Ridge National Laboratory, Report ORNL/Sub-88-SC863, February 1992.

27. Report of the Commission to Assess the Threat to the United States from Electromagnetic Pulse (EMP) Attack. Critical National Infrastructures, April 2008.

28. High Altitude Electromagnetic Pulse (HEMP) and High Power Microwave (HPM) Devices: Threat Assessments. CRS Report for Congress, July 2008.

29. The Early-Time (E1) High-Altitude Electromagnetic Pulse (HEMP) and Its Impact on the U.S. Power Grid. Report MetaR-320, Metatech Corp., January 2010.

30. The Late-Time (E3) High-Altitude. Electromagnetic Pulse (HEMP) and Its Impact on the U.S. Power Grid. Report MetaR-321, Metatech Corp., January 2010.

31. Intentional Electromagnetic. Interference (IEMI) and Its Impact on the U.S. Power Grid. Report Meta-R-323, Metatech Corp., January 2010.

32. High-Frequency Protection Concepts for the Electric Power Grid. Report Meta-R-324, Metatech Corp., January 2010.

33. Protection of High Voltage Power Network Control Electronics Against Intentional Electromagnetic Interference (IEMI). Report CIGRE Working Group C4.206, November 2014.
34. IEC TR 61000-1-3 Electromagnetic compatibility (EMC) Part 1-3: General - The effects of high-altitude EMP (HEMP) on civil equipment and systems.

35. IEC 61000-2-9 Electromagnetic compatibility (EMC) - Part 2: Environment - Section 9: Description of HEMP environment - Radiated disturbance. Basic EMC publication.

36. IEC 61000-2-10 Electromagnetic compatibility (EMC) Part 2-10: Environment - Description of HEMP environment Conducted disturbance.

37. IEC 61000-2-11 Electromagnetic compatibility (EMC) Part 2-11: Environment - Classification of HEMP environments.

38. IEC 61000-2-13 Electromagnetic compatibility (EMC) Part 2-13: Environment - High-power electromagnetic (HPEM) environments - Radiated and conducted.

39. IEC/TR 61000-5-3 Electromagnetic compatibility (EMC) Part 5-3: Installation and mitigation guidelines - HEMP protection concepts.

40. IEC/TS 61000-5-4 Electromagnetic compatibility (EMC) Part 5: Installation and mitigation guidelines - Section 4: Immunity to HEMP - Specifications for protective devices against HEMP radiated disturbance. Basic EMC Publication.

41. IEC 61000-5-5 Electromagnetic compatibility (EMC) - Part 5: Installation and mitigation guidelines - Section 5: Specification of protective devices for HEMP conducted disturbance. Basic EMC Publication.

42. IEEE P1642 Recommended Practice for Protecting Public Accessible Computer Systems from Intentional EMI.

43. Topic SEC-2011.2.2-2 Protection of Critical Infrastructure (structures, platforms and networks) against Electromagnetic (High Power Microwave (HPM)) Attacks, European Commission Security Research Program, 2010.

44. MIL-STD-188-125-1. High-Altitude Electromagnetic Pulse (HEMP) Protection for Ground-Based C4I Facilities Performing Critical Time-Urgent Missions, Department of Defense, 1994.

45. MIL-STD-461E. Requirements for the Control of Electromagnetic Interference Characteristics of Subsystems and Equipment, Department of Defense, 1993.

46. MIL-STD-464C. Electromagnetic Environmental Effects Requirements for Systems, Department of Defense, 1997.

47. MIL-STD-2169B. High Altitude Electromagnetic Pulse (HEMP) Environment, Department of Defense, 1993.

48. MIL-Hdbk-423. Military Handbook: High Altitude Electromagnetic Pulse (HEMP) Protection for Fixed and Transportable Ground-Based C41 Facilities, vol. 1: Fixed Facilities Department of Defense, 1993.

49. High Altitude Electromagetic Pulse (HEMP) Testing, Test Operations Procedure 01-2-620, U. S. Army Test and Evaluation Command, 2011.

50. Gurevich V. Protecting Power Systems from Destructive Electromagnetic Fields. Energize, 2015, April, pp. 36-37.

Received 03.07.2015

Vladimir I. Gurevich, Ph.D, Senior specialist,

Central Electric Laboratory of Israel Electric Corp.

31000, Israel, Haifa, POB 10,

e-mail: vladimir.gurevich@gmx.net 